Article

\title{
Bacillales Members from the Olive Rhizosphere Are Effective Biological Control Agents against the Defoliating Pathotype of Verticillium dahliae
}

\author{
Carmen Gómez-Lama Cabanás ${ }^{1}$, David Ruano-Rosa ${ }^{2}$ (D), Garikoitz Legarda ${ }^{3}$, \\ Paloma Pizarro-Tobías 4 (10), Antonio Valverde-Corredor ${ }^{1}$, Juan Carlos Triviño ${ }^{3}$, Amalia Roca ${ }^{4}$ \\ and Jesús Mercado-Blanco ${ }^{1, *(\mathbb{D})}$ \\ 1 Department of Crop Protection, Institute for Sustainable Agriculture (CSIC), Avenida Menéndez Pidal s/n \\ Campus 'Alameda del Obispo', 14004 Córdoba, Spain; cgomezlama@ias.csic.es (C.G.-L.C.); \\ valverde@ias.csic.es (A.V.-C.) \\ 2 Unit of Woody and Horticultural Crops, Agrarian Technological Institute of Castilla y León, \\ Ctra. Burgos Km 119, Finca Zamadueña, 47071 Valladolid, Spain; ruanodavid@gmail.com \\ 3 Bioinformatics Department, Sistemas Genómicos S.L., 46980 Paterna, Spain; \\ garikoitz.legarda@sistemasgenomicos.com (G.L.); jc.trivino@sistemasgenomicos.com (J.C.T.) \\ 4 Bio-Ilíberis Research and Development SL, Polígono Industrial Juncaril, C/Capileira 7, \\ 18210 Peligros (Granada), Spain; ppizarro@bioiliberis.com (P.P.-T.); aroca@bioiliberis.com (A.R.) \\ * Correspondence: jesus.mercado@ias.csic.es; Tel.: +34-95-749-9261
}

Received: 15 June 2018; Accepted: 19 June 2018; Published: 23 June 2018

\begin{abstract}
The use of biological control agents (BCAs) is of interest within an integrated management strategy of Verticillium wilt of olive (VWO) caused by the soil-borne fungus Verticillium dahliae Kleb. Previous studies have shown that the root/rhizosphere of healthy olive plants is an important reservoir of microorganisms displaying biocontrol activity against VWO (i.e., Pseudomonas strains PICF7 and PIC141). Moreover, these BCAs are already adapted to the ecological niche where they are deployed. Three novel bacteria (strains PIC28, PIC73 and PIC167) from nursery-produced olive plants were in-depth characterized using a previously implemented approach consisting of in situ isolation, in vitro antagonism tests, in planta bioassays, phenotypic and metabolic characterization, genome analyses and in silico identification of traits involved in plant-bacteria interactions, and multi-locus sequence analyses. All strains displayed in vitro growth inhibition of different olive pathogens and biocontrol effectiveness against Verticillium dahliae, with strain PIC73 being the most effective BCA. Strains PIC73 and PIC167 were identified as Paenibacillus polymyxa (Prazmowski) Ash et al. and Paenibacillus terrae Yoon et al., respectively. Strain PIC28 belongs to the Bacillus genus. Some of these Bacillales members showed in vitro compatibility with previously characterized BCAs (Pseudomonas spp. strains) also originating from the olive rhizosphere, paving the way for the future development of tailored bacterial consortia effective against VWO.
\end{abstract}

Keywords: Bacillus; biocontrol; Olea europaea; Paenibacillus polymyxa; Paenibacillus terrae; Verticillium wilt

\section{Introduction}

Verticillium wilt of olive (VWO) is one of the most serious diseases affecting olive (Olea europaea L. subsp. europaea var. europaea) cultivation worldwide. Verticillium dahliae Kleb., the causal agent of VWO, is responsible for substantial production losses thereby constituting the main phytopathological issue in many olive-growing regions. Multiple factors explain the current spread and importance of the disease: the long-term endurance of microsclerotia (resistance structures of $V$. dahliae) in soil, the broad host range of the pathogen, the vascular nature of the disease, inappropriate agronomical practices, etc. [1]. 
All these factors make it difficult for an efficient control of VWO, and available measures have so far proven unsuccessful when implemented individually. Therefore, an integrated disease management strategy is recommended, highlighting pre-plating control tools since no resistant varieties and/or effective fungicides are available. Within this context, the development and use of biological control agents (BCAs) is an appealing, sustainable and environmentally friendly management approach to control VWO.

Biocontrol experiments are often carried out using sterile soils/substrates; therefore, major determinants influencing results are nutrient availability and/or soil physico-chemical conditions [2]. Moreover, these bioassays are frequently performed using plants artificially inoculated via root dipping in (or soil drenching with) the pathogen's conidia suspensions. However, this experimental scenario is quite different to the situation taking place under field conditions. For instance, in sterile soils there is no competence with other microorganisms and the BCA can easily be established. When several microorganisms are used at the same time under these very specific (and artificial) conditions, the final outcome is strongly determined by the inherent capability of each microorganism to multiply and prevail over the others. In contrast, under natural soil conditions, the introduced BCAs face a very complex situation in a harsh environment considered as one of the most microbiologically diverse on earth [3]. This is particularly true when the introduced microorganism is not adapted to the target ecological niche.

The use of BCAs under greenhouse or nursery conditions is easier, cheaper, and less time-consuming than large-scale field treatments which, in addition, often suffer from inconsistency or lack of effectiveness. Hence, implementing biological control measures to protect woody plants (e.g., olive) at the propagation stage (i.e., greenhouses or nurseries) against soil-borne pathogens like $V$. dahliae appears as a preventive and recommendable approach. This 'pretreatment strategy' can be performed before olive plants are transferred to the field, usually cultivated in large growing areas where biocontrol approaches are often unfeasible both from economical and agronomical perspectives [4].

Our current knowledge on fungi, oomycetes and bacteria as effective BCAs against $V$. dahliae infecting different crops is steadily increasing (reviewed by [5]). Berg et al. [6] already demonstrated that naturally occurring rhizobacteria are effective BCA against $V$. dahliae. Zhengjun et al. [7] reported on rhizosphere and endophytic bacteria able to control Verticillium wilt of cotton. Berg and Lottmann [8] informed that Verticillium wilt of oilseed rape could be controlled by a Stenotrophomonas maltophilia (Hugh) Palleroni and Bradbury. strain. Tjamos et al. [9] selected two Bacillales strains, Bacillus sp. 5-27 and Paenibacillus alvei K-165, from root tips of tomato plants grown in solarized soils able to inhibit $V$. dahliae's growth and to successfully control Verticillium wilt. The use of strain K-165 also reduced germination of $V$. dahliae microsclerotia in root tips and in the root elongation zone of eggplants [10]. Malandraki et al. [11] selected two strains of the Pseudomonas fluorescens Migula. complex and two isolates of the Fusarium oxysporum Schltdl. complex, all capable to reduce disease severity in eggplants. Likewise, Veloso and Díaz [12] demonstrated that inoculation of pepper plants with the nonpathogenic isolate F. oxysporum 47 reduced Verticillium wilt blight symptoms. Regarding biocontrol of $\mathrm{VWO}$, advances are still limited, although some examples have shown promising results. For instance, olive root-associated fluorescent pseudomonads have been demonstrated to control VWO caused by the highly virulent, defoliating (D) pathotype of $V$. dahliae in young, nursery-produced plants [13-16]. Paenibacillus alvei K-165 has also been shown to suppress VWO under both greenhouse and field conditions [17]. Finally, Acetobacter aceti VIN02 reduced the percentage of mortality in V. dahliae-inoculated plants to the level observed in non-inoculated plants [18]. However, even though several microorganisms have been shown to be effective BCAs against Verticillium wilt, hardly any of them are available as biopesticides against Verticillium in Europe [19].

Disease suppressive soils, organic amendments, and healthy plants enduring in pathogen-infested fields are interesting reservoirs of potential BCAs [5,11,16,20]. Microbial communities associated with plant roots are complex and diverse, and they strongly influence the health and development of the 
host [21]. Moreover, the rhizosphere microbiome plays a significant role in reprogramming defense responses of plants [22]. Therefore, to look for beneficial indigenous microbial inhabitants adapted to the conditions found in the olive root/rhizosphere seems to be a good strategy to identify novel BCAs candidates against VWO. In a previous study, we designed a holistic approach to identify, characterize and evaluate new and effective BCAs originating from the roots of healthy nursery-propagated olive plants [16]. This strategy was based on the isolation from the target niche, in vitro antagonism assays against relevant olive pathogens (V. dahliae, Phytophthora cinnamomi Rands., Pseudomonas savastanoi (Janse) Gardan et al.), phenotypic and metabolic characterization in order to identify traits associated with biological control or plant growth promotion (PGP), in planta experiments under non-gnotobiotic conditions to assess their effectiveness against the $\mathrm{D}$ pathotype of $V$. dahliae, genome sequencing and in silico analysis, taxonomic identification by multi-locus sequence analyses (MLSA), and evaluation of root colonization abilities [16]. Eventually, we were able to identify and in-depth characterized three novel Gram-negative resident olive rhizobacteria belonging to the Pseudomonas genus (namely, strains PIC25, PIC105 and PICF141) showing good biocontrol ability against VWO. Current research trends in biocontrol aim to investigate the role and effectiveness of microbial consortia, synthetic communities and even tailored microbiomes in promoting plant growth and/or defense against pathogens $[23,24]$. The use of bacterial consortia to control soil-borne pathogens may have the advantage over single microbe-based formulations to enhance biocontrol effectiveness. Indeed, the introduction of diverse beneficial microbes may facilitate the colonization of different microhabitats on/in roots thereby enhancing competition for colonization sites used by the pathogen. Furthermore, a range of biocontrol mechanisms can be deployed by each BCA in the consortium contributing in this manner to improved disease suppressiveness [25].

This study aims to identify and characterize Gram-positive bacteria from the olive root/rhizosphere with potential as BCAs against olive pathogens, with emphasis on $V$. dahliae. We implemented the same comprehensive strategy that previously yielded successful results when screening and evaluating indigenous beneficial Pseudomonas spp. An additional aim was to in vitro assess whether combinations of these previously verified BCAs and the newly described antagonists here reported, all adapted to the olive rhizosphere, could be formulated as consortia to control VWO.

\section{Materials and Methods}

\subsection{Olive Roots Sampling and Bacterial Isolation}

This study focused on three Gram-positive strains (namely PIC28, PIC73 and PIC167) of an olive rhizobacteria collection obtained from roots of one-year-old 'Picual' plants, a cultivar qualified as highly susceptible to $V$. dahliae [26], collected from ten commercial nurseries located in Córdoba province (South Spain). Experimental details on olive roots sampling, bacteria isolation and their preliminary identification, and generation of the olive rhizobacteria collection have been previously described [27]. Briefly, individual root tissue samples (three plants per nursery) were ground using a mortar and pestle. Aliquots of 10-fold serial dilutions of the macerates obtained from each sample were plated on different culturing media: potato dextrose agar (PDA; Oxoid Ltd., Basingstoke, Hampshire, UK), LuriaBertani agar (LBA; Oxoid Ltd., Basingstoke, Hampshire, UK) and nutrient agar (NA; Oxoid Ltd., Basingstoke, Hampshire, UK). Plates were incubated at $28{ }^{\circ} \mathrm{C}$ in the dark for at least $72 \mathrm{~h}$. Single colonies grown in these media showing distinctive morphological characteristics were selected and isolated. Each colony were cryopreserved as described [27] until use.

\subsection{DNA Isolation, Molecular Identification and Phylogenetic Analysis of Selected Olive Rhizobacteria}

Total DNAs from bacteria were extracted using the 'JETFLEX Genomic DNA Purification Kit' (Genomed Ltd., Harrow, Middlesex, UK) according to the manufacturer's instructions. Bacteria were molecularly identified (at least at the genus level) by partial sequencing of the gyrB gene. PCR experiments and purification of DNA fragments were performed as previously described [27]. 
PCR products were sequenced at Sistemas Genómicos S.L. (Paterna, Valencia, Spain) and assembled in 'contigs' using the 'CLC Main Workbench' (version 7.6.4, CLC Bio, Qiagen, Aarhus, Denmark). The genus/species of the strains under study were identified by comparing the resulting contigs with NCBI Blast using the BLASTN algorithm [28].

An MLSA (5717 nt positions) was conducted using partial sequences of several housekeeping genes: gyrB (1582 nt), atpA (1518 nt), nusA (758 nt), pyrH (732 nt) and dnaJ (1127 nt) in order to refine the taxonomic position of strains PIC28, PIC73 and PIC167 previously obtained by just comparing the gyrB gene sequence. Gene sequences, except that of the $g y r B$ gene, were obtained from the three genomes here sequenced (see below) and then compared with homolog sequences of ad hoc selected Bacillus spp. (13) and Paenibacillus spp. (15) type strains retrieved from different public databases, (i.e., NCBI, EMBL, KEGG, etc.), and that were phylogenetically related to the three olive rhizobacteria under study. A circular dendrogram was then constructed with Molecular Evolutionary Genetics Analysis version 7 (MEGA7) [29], using the Neighbor-Joining algorithm. For this phylogenetic tree Paenibacillus larvae dsm 25,430 was used as out-group species. Bootstrap analyses of 1000 replications were performed. Distance matrixes were generated using the Maximum Composite Likelihood model [30] with MEGA7 [29], and percentages identity of the concatenated sequences were inferred with the Clustal 2.1 version.

\subsection{In Vitro Antagonism Tests}

Strains PIC28, PIC73 and PIC167 were in vitro tested to assess their growth inhibition ability against several olive pathogens (Table 1), following an experimental setup previously described [16,27]. In addition, and in order to quantify the growth inhibition degree of $V$. dahliae, antagonism tests against a representative of the D pathotype (strain Lebrija 1, [16]) were carried out. Individual drops $(10 \mu \mathrm{L})$ containing $V$. dahliae biomass (i.e., mycelium plus conidia, $1 \times 10^{6}$ conidia $/ \mathrm{mL}$ ) were placed in the middle of PDA plates, and four equidistant $10-\mu \mathrm{L}$ drops of each bacterial strain $\left(1 \times 10^{8} \mathrm{ufc} / \mathrm{mL}\right)$ were inoculated. Control plates containing only an individual drop of the pathogen biomass were included in each assay. The relative inhibition index was calculated according to the equation (Rc-Ra)/Rc, where Rc is the average radius of $V$. dahliae colony in the absence of the antagonist bacterium and $R a$ is the average radius of $V$. dahliae colony in the presence of the antagonist bacterium (four equidistant points). This experiment was repeated once including three biological replicates per each pathogen-BCA interaction. Statistical significance was determined by ANOVA analysis of the relative inhibition index. The Tukey HSD Test at $p=0.05$ was applied for comparison of mean values by using the analytical software 'Statistix' (Version 10.0 for Windows, 1985-2013, Tallahassee, FL, USA).

\subsection{Biocontrol Ability of Selected Olive Rhizobacteria Against Verticillium Dahliae D Pathotype}

Two independent biocontrol experiments were carried out under non-gnotobiotic conditions to test the ability of the three selected strains, PIC28, PIC73 and PICF167, to control VWO. In these bioassays strains P. fluorescens PICF7 [31] and Pseudomonas sp. PICF141 [16] were included for comparative purposes because of their well-known biocontrol activity. Fifty-four (Experiment I; ExpI) ninety and (Experiment II; ExpII) 'Picual' plants (5-month-old) were grown in pots $(11 \times 11 \times 11 \mathrm{~cm}$; one plant per pot), each containing $300 \mathrm{~g}$ of potting substrate used in the nursery, and distributed in three random blocks (nine plants in ExpI and fifteen plants in ExpII per treatment) within a greenhouse under natural lighting and day/night temperature of $27 / 21^{\circ} \mathrm{C}$. For each bacterial treatment, olive plants were inoculated as described by Gómez-Lama Cabanás and co-workers [16]. Control plants were only amended with $150 \mathrm{~mL}$ of $\mathrm{SO}_{4} \mathrm{Mg} \cdot 7 \mathrm{H}_{2} \mathrm{O} 10 \mathrm{mM}$. One week after bacterization, plants were inoculated with isolate V937I of $V$. dahliae, representative of the D pathotype, as previously described [16]. Disease progress was assessed twice a week by scoring the severity of symptoms on a $0-4$ scale according to the percentage of affected leaves and twigs ( 0 , no symptoms; $1,1-33 \%$; 2, 34-66\%; 3, 67-100\%; 4, dead plant) during 90 days after pathogen inoculation [15]. Parameters such as Disease Incidence (DI), Mortality (M), and a Disease Intensity Index (DII) were also calculated for each treatment. This latter parameter was defined as DII $=(\Sigma \mathrm{Si} \times \mathrm{Ni}) /(4 \times \mathrm{Nt})$, where $\mathrm{Si}$ is severity of 
symptoms, $\mathrm{Ni}$ is the number of plants with $\mathrm{Si}$ symptoms severity, and $\mathrm{Nt}$ the total number of plants. A final DI was also established as the percentage of affected plants at the end of the experiments. Finally, the area under the disease progress curve (AUDPC) over time (days; [32]) and the final severity were calculated. Statistical significance was determined by ANOVA. The Fisher's protected LSD Test at $p=0.05$ was applied for comparison of mean values by using the analytical software 'Statistix' (Version 10.0 for Windows, 1985-2013, Tallahassee, FL, USA).

\subsection{Phenotypic and Metabolic Characterization of Olive Rhizobacteria}

The ability of strains PIC28, PIC73 and PICF167 to produce HCN, siderophores, the phytohormone indole acetic acid (IAA) and the volatile 2,3-butanediol, and to display enzymatic activities such as protease, catalase, phosphatase, chitinase, phytase, cellulase, xylanase, $\beta$-glucosidase, glucanase, pectinase and amylase was evaluated to identify phenotypes traditionally associated with biological control or PGP. For such an aim, the procedures described by Gómez-Lama Cabanás and co-workers ([16]; and references therein) were implemented. The GEN III MicroPlate ${ }^{\mathrm{TM}}$ system $^{2}$ (Biolog, Hayward, CA, USA) was used to obtain the phenotypic profiles of the three olive rhizobacteria here under study. These plates contain 71 carbon sources and 23 antimicrobials. This system analyzes the ability of a tested microorganism to metabolize a range of compounds, as well as enables to determine important physiological properties such as $\mathrm{pH}$, salt and lactic acid tolerance, reducing power, and chemical sensitivities. Bacteria suspensions were prepared as recommended by the manufacturer. All these experiments were performed at least twice.

\subsection{Genome Sequencing and Bioinformatics Analysis}

The genomes of strains PIC28, PIC73, and PIC167 were sequenced according to a previously described strategy [16] at Sistemas Genómicos S.L. (Paterna; Valencia, Spain). The sequencing was made with a final size of $300 \mathrm{bp}$ for the paired-end reads. Total initial reads were 3,361,104 paired-ends giving a fold coverage of 193.67 for PIC73, 3,061,700 paired-ends (168.36X) for PIC28, and 2,278,298 paired-ends (130.81X) for PIC167. The quality of the raw data was measured and checked using FASTQC tools [33]. Illumina Truseq adaptors were removed with the Fastq mcf [34] (v1.04.803) tool, and then a quality filter was made with Cutadapt [35] (v1.9.1) using a quality window value of 30. With the reads clean, the R1 and R2 paired-end reads were merged using Flash [36] (v1.2.11). With a masking step for the low-quality bases and another for complexity reduction, the reads were ready to be assembled. The assemblers used were mainly Megahit [37] (v1.0.3-29-g707d683) and Velvet [38] (v1.2.10). Several k-mer sizes were used, from 71 to 99 . The best assemblies were selected using the best $\mathrm{N} 50$ criteria, and over this selected assembly the annotation process was made using Glimmer3 [37-40] for the ORF detection. Blast V.2.2.30+ [41] with an E-value cutoff of $1 \mathrm{e}^{-3}$ against the latest version (UniProtKB/Swiss-Prot Release 2015_08) of the Uniprot Swissprot protein curated database for bacteria [42] was used for the annotation. The small local alignments were removed from the Blast result file applying a filter. All the sequences without a hit after removing the small local alignments, were annotated using Blast V.2.2.30+ [41] as previously described [16]. Identified genes were functionally annotated using functional annotation of Uniprot database according to the three different functional categories; biological process, molecular function and cellular component from Gene Ontology [43]. To improve the understanding of the sequenced genomes and their arrangements, each one of them was aligned to the closest relative species available at NCBI [28] using Projector2 [44]. The new pseudoassembly sequences were processed again using Glimmer3 [40] and the new ORFs were annotated with Blast V.2.2.30+ [41] against Uniprot (The Universal Protein Resource Database, 2008) [42] for the functional annotation. The associated Kegg Ontology pathways [45], Gene Ontology [43] and PFam [46] terms were obtained to count and sort them in order to create a functional view of the differences. Genome sequences were deposited at Genbank under the accession IDs SAMN08323495, SAMN08323496 and SAMN08323497 for PIC28, PIC73 and PIC167, respectively. 


\subsection{In Silico Identification of Genetic Factors Involved in Plant-Bacteria Interactions}

'PIFAR' web-based tool [47] was used to identify genetic factors involved in the interaction of bacteria with host plants. Thus, the presence of genes related to adhesion, antibiotic production, biofilm, detoxification, secretion of exopolysaccharides (EPSs), bacterial lipopolysaccharides (LPSs), microbe-associated molecular patterns (MAMPs), multidrug resistance (MDRs), plant cell wall-degrading enzymes (PCWDEs), phytohormones, phytotoxins, pigmentation, proteases, siderophores, type III effectors and volatiles was investigated in the three olive rhizobacteria genomes under study. Furthermore, by using the 'T346Hunter' web-based tool [48] we also aimed to uncover the presence of three types of bacterial secretion systems (TSS), namely flagellar and non-flagellar type III secretion systems (T3SS), type IV (T4SS) and type VI (T6SS). Finally, since an indispensable prerequisite for the use of BCAs in agriculture is the absence of undesirable traits (i.e., genetic factors potentially deleterious for plants, animals and humans), the annotated genomes of the three selected rhizobacteria were manually examined in order to discard the presence of genes potentially involved in pathogenesis/virulence processes.

\subsection{In Vitro Antagonism among Olive Rhizobacteria Displaying Biocontrol Against VWO}

In order to evaluate whether well-characterized Pseudomonas spp. strains indigenous to olive roots and with demonstrated biocontrol activity against VWO (i.e., strains PIC25, PIC105, PICF141 [16] and PICF7 [31]) could be combined and used in future formulations (consortia of BCAs) with the Bacillales members described in this study, in vitro antagonism tests were carried out. Four drops $\left(5 \mu \mathrm{L}, 10^{7} \mathrm{cfu} \mathrm{mL}^{-1}\right.$ ) of each strain (challenger) were placed on the surface of LBA (Luria Bertani Agar) and PDA media plates previously inoculated with $100 \mu \mathrm{L}$ of a bacterial suspension of each strain $\left(10^{6} \mathrm{cfu} \mathrm{mL}^{-1}\right)$ (target) in all possible combinations. Two series of plates (two per assayed media) were incubated at $28{ }^{\circ} \mathrm{C}$ in the dark, and after $48 \mathrm{~h}$, bacterial growth and presence/absence of inhibition halos around colonies were observed. For each combination, the assay was performed twice.

\section{Results}

\subsection{Molecular Identification and Phylogenetic Analysis of Newly Isolated Olive Rhizobacteria}

The gyrB sequences (amplicon size $\approx 1200 \mathrm{bp}$ ) of the three olive rhizobacteria were compared to sequences deposited on GenBank using a BLASTn search. The analysis enabled us to identify the three strains as members of the order Bacillales. Strain PIC28 showed high identity (99\%, e-value 0.0) with two different species from the Bacillus genus, Bacillus cereus Frankland and Frankland. (strain C1L) and Bacillus thuringiensis serovar canadensis (strain IEBC-T05A001). Therefore, the gyrB gene sequence did not allow the accurate identification (species level) of this strain. In contrast, strain PIC73 could be unambiguously identified as Paenibacillus polymyxa (Prazmowski) Ash et al. (99\% identity, e-value 0.0), and strain PIC167 as Paenibacillus terrae Yoon et al. (96\% identity, e-value 0.0).

In order to more accurately identify the three novel Bacillales strains, an MLSA (5717 nucleotide positions) of concatenated partial sequences of the housekeeping genes gyrB, atp $A, n u s A, p y r H$ and $d n a j$, that were obtained from their sequenced genomes (see below) was performed. A phylogenetic tree was then generated including our three olive rhizobacteria and 13 Bacillus spp. type strains belonging to five different species and 15 Paenibacillus spp. type strains belonging to 12 different species (Figure 1). Results enabled to assign strains PIC73 and PIC167 to P. polymyxa and P. terrae species, respectively, in agreement with the preliminary molecular identification only based on $g y r B$ gene sequences comparison. However, strain PIC28 clustered ambiguously among different Bacillus species (Figure 1), B. cereus (89\% identity) and B. thuringiensis Berliner. (89.59\% identity) being the closest relatives. Therefore, this strain was kept as incertae sedis within the Bacillus genus until further evidence. 


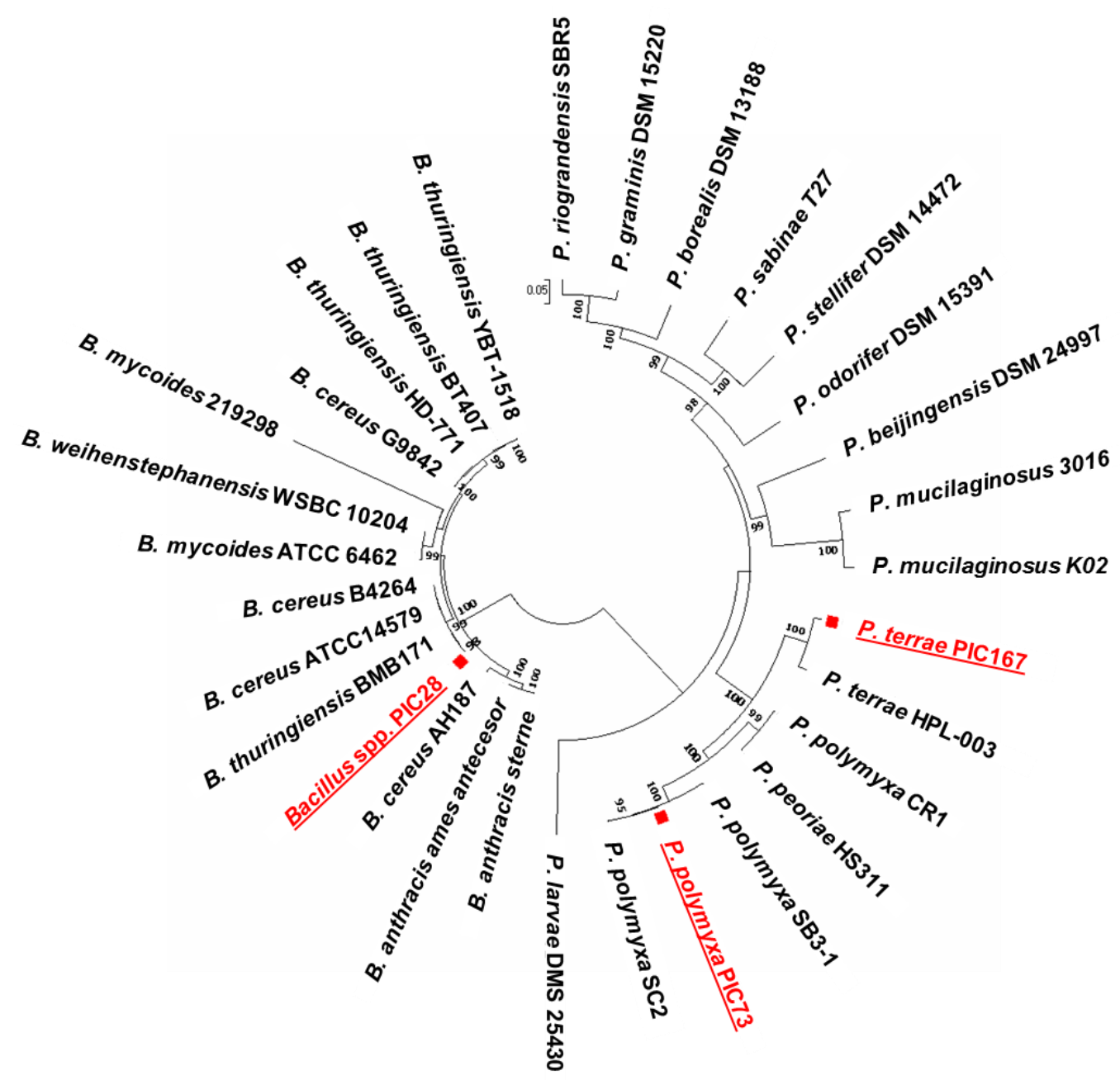

Figure 1. Circular phylogenetic tree showing the taxonomic position of the three novel Bacillales strains (underlined red color) isolated from olive 'Picual' roots. The tree was constructed by the Neighbor-Joining method, based on the alignment of concatenated partial sequences of $g y r B$, atp $A$, $n u s A$, pyrH and $d n a J$ (see text for details). Bar indicates sequence divergence. Bootstrap values ( $\geq 95 \%$ ) based on 1000 re-sampled datasets are shown at branch nodes. Paenibacillus larvae DMS 25430 was used as out-group.

3.2. Bacillales from Olive Roots Showed In Vitro Antagonism Against Different Olive Pathogens, Including Verticillium dahliae

Results from in vitro antagonism tests showed that the three Bacillales strains originating from olive roots were able to inhibit the growth of different olive pathogens at variable levels (Table 1). The two Paenibacillus spp. strains (PIC73 and PIC167) effectively antagonized all pathogens tested (i.e., V. dahliae, Rosellinia necatrix Prill., P. cinnamomi, Colletotrichum nymphaeae Aa., Colletotrichum godetiae Neerg. and P. savastanoi) at least in one out the two culturing media assayed. However, Bacillus sp. PIC28 was effective neither against $R$. necatrix nor one P. savastanoi strain (Table 1 ). Inhibition of pathogen growth depended on the medium used (PDA or NA). When in vitro antagonism tests against $V$. dahliae were performed to calculate a relative inhibition index, the three olive rhizobacteria were able to significantly $(p<0.05)$ inhibit the growth of $V$. dahliae D pathotype, with strain PIC73 showing the highest antagonistic capacity. Relative inhibition indices differed among strains (PIC73 = $0.49 \mathrm{a}$, PIC167 $=0.47 \mathrm{ab}$, and PIC28 $=0.45 \mathrm{~b}$ ). According to these results, the three olive rhizobacteria would be promising BCA candidates against VWO. 
Table 1. Results from in vitro antagonism tests against relevant olive pathogens.

\begin{tabular}{|c|c|c|c|c|c|c|c|c|c|c|c|c|c|c|c|c|c|c|}
\hline \multirow{2}{*}{$\begin{array}{c}\text { Olive Pathogens } \\
\text { Media }\end{array}$} & \multicolumn{2}{|c|}{ Vd Lebrija1 } & \multicolumn{2}{|c|}{ Vd V-249I } & \multicolumn{2}{|c|}{ Rn 320} & \multicolumn{2}{|c|}{ Rn 400} & \multicolumn{2}{|c|}{ Pc } & \multicolumn{2}{|c|}{ Psv PSS3 } & \multicolumn{2}{|c|}{ Psv NCPPB 3335} & \multicolumn{2}{|c|}{ Col.114 } & \multicolumn{2}{|c|}{ Col.516 } \\
\hline & PDA & NA & PDA & NA & PDA & NA & PDA & NA & PDA & NA & PDA & NA & PDA & NA & PDA & NA & PDA & NA \\
\hline PIC28 & + & + & + & - & - & - & - & - & - & + & + & - & - & - & + & + & + & + \\
\hline PIC167 & + & + & + & + & + & + & - & + & + & + & + & + & - & + & + & + & + & + \\
\hline
\end{tabular}

Vd, Verticillium dahliae; Rn, Rosellinia necatrix; Pc, Phytophthora cinnamomi; Psv, Pseudomonas savastanoi pv. savastanoi; Col.114, Colletotrichum nymphaeae; Col.516, Colletotrichum godetiae. + , positive antagonism against the pathogen; - no antagonism. At least two biological replicates for each confrontation and culturing media were performed. PDA, Potato Dextrose Agar; NA, Nutrient Agar. 


\subsection{Strains PIC28, PIC73 and PIC167 Control VWO Under Greenhouse Conditions}

Overall, results from independent biocontrol experiments ExpI and ExpII showed that 'Picual' plants pretreated with each of the three selected olive rhizobacteria reduced VWO development, as evidenced by a significant $(p<0.05)$ reduction of the AUDPC compared to non-bacterized plants, as well as other phytopathological parameters scored (final DI and DII, mortality and severity) (Table 2). In fact, the three Bacillales strains showed a good biocontrol ability against the D pathotype of $V$. dahliae as that displayed by P. fluorescens PICF7 and Pseudomonas sp. PICF141, two well-studied BCAs of VWO here used for comparative purposes. Non-inoculated plants (control treatment) and plants inoculated only with the bacterial strains showed normal growth in the two bioassays carried out. Neither abnormal appearance nor unexpected symptoms were observed during the bioassays. While all bacterial/ $V$. dahliae treatments reduced the AUDPC compared with control (non-bacterized) plants, no significant difference in biocontrol performance was observed among olive rhizobacteria in ExpI (Table 2). Likewise, parameters such as final DI and DII, mortality, and severity were also reduced in all BCA treatments. However, in ExpII disease pressure was higher and Pseudomonas strains overall performed better than the Bacillales members. At the end of this bioassay, all BCA/Vd treatments showed significantly $(p<0.05)$ lower AUDPC values compared with the control (non-bacterized) treatment, although strains PIC73 and PIC167 performed slightly better than PIC28 for all disease parameters scored (Table 2). The three newly identified indigenous olive Gram-positive rhizobacteria were thus able to significantly reduce VWO progress under our experimental conditions, particularly when disease pressure was moderate.

Table 2. Biocontrol performance of Bacillales members against the defoliating pathotype of Verticillium dahliae.

\begin{tabular}{|c|c|c|c|c|c|c|c|c|c|c|}
\hline \multirow{3}{*}{ Treatments } & \multicolumn{5}{|c|}{ Experiment I } & \multicolumn{5}{|c|}{ Experiment II } \\
\hline & \multicolumn{5}{|c|}{ Disease Parameters $^{1}$} & \multicolumn{5}{|c|}{ Disease Parameters $^{1}$} \\
\hline & AUDPC & Final DI (\%) & Final DII & M (\%) & $S$ & AUDPC & Final DI (\%) & Final DII & M (\%) & $\mathbf{S}$ \\
\hline V. dahliae/PIC73 & $48.40 \mathrm{~b}$ & 33.33 & 0.33 & 33.33 & 1.33 & $93.34 \mathrm{bc}$ & 86.67 & 0.71 & 53.33 & 2.38 \\
\hline V. dahliae/PIC167 & $38.83 \mathrm{~b}$ & 33.33 & 0.33 & 33.33 & 1.33 & $108.23 \mathrm{~b}$ & 86.67 & 0.78 & 73.33 & 2.66 \\
\hline V. dahliae/PICF141 & $22.83 \mathrm{~b}$ & 20.00 & 0.29 & 11.11 & 1.16 & $65.05 c$ & 73.33 & 0.58 & 33.33 & 1.86 \\
\hline
\end{tabular}

${ }^{1}$ AUDPC, area under the disease progress curve (90 days). Final DI, final disease incidence (\%). Final DII, disease intensity index (ranging 0-1) calculated with data on incidence and severity of symptoms ( 90 days). M, dead plants at the end of the experiment (\%) (90 days). S, mean of disease severity symptoms (from 0 to 4 ) at the end of the experiments (90 days). Data are the average of three randomly distributed blocks each with three and five pots per treatment in Experiments I and II, respectively. Non-inoculated plants did not show any disease symptom and were excluded for statistical analysis. In each column, values followed by different letters are significantly different according to contrast Fisher's protected LSD test $(p=0.05)$.

\subsection{Identification of Phenotypes Associated with Biological Control or Plant Growth Promotion}

All strains were positive for protease, cellulase, $\beta$-glucosidase and catalase activities, as well as for siderophore(s) and 2,3-butanediol production. Strains PIC73 and PIC167 showed a higher number of positive activities than strain PIC28, including production of chitinase, amylase and xylanase. None of them were positive for the production of HCN or for pectinase and IAA activities (Table 3). Very weak phosphatase and glucanase activities were detected only for P. polymyxa PIC73. Strain PIC167 was the only strain showing phytase activity (Table 3 ). 
Table 3. Screening of activities associated with plant growth promotion or biocontrol in Bacillales strains.

\begin{tabular}{|c|c|c|c|c|c|c|c|c|c|c|c|c|c|c|c|}
\hline \multirow{2}{*}{ Isolate } & \multicolumn{15}{|c|}{ Activities } \\
\hline & Siderophores & Protease & Cellulase & B-Glucosidase & Catalase & 2,3-Butanediol & Phytase & Chitinase & Amylase & Xylanase & Phosphatase & Glucanase & Pectinase & IAA & $\mathrm{HCN}$ \\
\hline PIC28 & + & + & + & + & + & + & - & - & - & - & - & - & - & - & - \\
\hline PIC73 & + & + & + & + & + & + & - & + & + & + & \pm & \pm & - & - & - \\
\hline PIC167 & + & + & + & + & + & + & + & + & + & + & - & - & - & - & - \\
\hline
\end{tabular}

+ , presence of activity; - , absence of activity; \pm , ambiguous result. Results shown were obtained from Luria Bertani Agar (LBA) cultures amended with L-glycine. At least two biological replicates for each activity/strain were performed. 
Results from the Biolog GEN III assays showed that Paenibacillus spp. strains (PIC73 and PIC167) shared most of the properties tested (85/94) (i.e., biochemical properties, utilization of carbon sources, chemical sensibilities) and differed only in a few metabolic characteristics (Supplementary Table S1). For instance, strain PIC167 was able to utilize L-aspartic acid, methyl piruvate, L-malic acid, bromo succinic acid and acetic acid, whereas strain PIC73 was unable to utilize any of these substrates but could grow, in contrast to PIC167, at $\mathrm{pH} 5$ and in the presence of $4 \% \mathrm{NaCl}$, rifamycin, lincomycin, guanidine $\mathrm{HCl}$ and niaproof 4 . The Biolog profile exhibited by strain PIC28 was clearly different from those of the Paenibacillus strains. For instance, only nine carbon sources were used by all three rhizobacteria. Moreover, PIC28 was the only strain showing tolerance to D-serine (Supplementary Table S1).

\subsection{Whole-Genome General Features of the Newly Identified Biocontrol Agents}

A general summary of the three genome sequencing projects is shown in Supplementary Table S2. The draft genomes of strains PIC28, PIC73 and PIC167 included 43, 31 and 18 large mapped contigs (largest contigs size were 1,384,757, 863,368 and 1,232,833 nucleotides, respectively) and 75, 22 and 7 non-mapped contigs, respectively. Additional relevant characteristics (genome size, GC content, predicted number of coding sequences, number of rRNA operons, etc.) are shown in Table 4. All these characteristics are within the range of previously sequenced genomes of Bacillus and Paenibacillus [49-51]. A total of 5905, 5716 and 5413 predicted genes were identified for PIC28, PIC73 and PIC167, respectively. Predicted genes annotated for each strain are listed in Supplementary Table S3. Approximately 4012, 3757 and 3598 of them were predicted as protein-coding genes. Functional categories for each coding DNA sequences according to the COG (Clusters of Orthologous Groups) are summarized in Supplementary Table S4.

Table 4. General information of Bacillales genomes.

\begin{tabular}{|c|c|c|c|}
\hline & & Strains & \\
\hline Attributes & PIC28 & PIC73 & PIC167 \\
\hline \multicolumn{4}{|l|}{ Contigs } \\
\hline Number of contigs & 43 & 31 & 18 \\
\hline Mean sizes of the contigs & $121,884.65$ & $177,159.39$ & $292,209.67$ \\
\hline Range of sizes of the contigs & $313-1,384,757$ & $329-863,368$ & $19,822-1,232,833$ \\
\hline Number of contigs with size $>5000$ & 21 & 23 & 18 \\
\hline Reads assembled as contigs & $5,600,608$ & $4,973,836$ & $3,576,880$ \\
\hline Percentage of the reads assembled & 83.31 & 81.22 & 78.49 \\
\hline \multicolumn{4}{|l|}{ Genome \& Genes } \\
\hline Genome size (bp) & $5,241,040$ & $5,491,941$ & $5,259,774$ \\
\hline DNA coding region (bp) & $4,504,311$ & $4,945,917$ & $4,749,285$ \\
\hline DNA G+C content & $34.95 \%$ & $45.14 \%$ & $46.69 \%$ \\
\hline Total genes & 5905 & 5716 & 5413 \\
\hline Protein-coding genes & $4012(67.93 \%)$ & $3757(65.71 \%)$ & $3598(66.45 \%)$ \\
\hline RNA genes & NA & NA & NA \\
\hline Protein-coding genes with function prediction and assigned to COGs & $4012(67.93 \%)$ & $3757(65.71 \%)$ & 3598 (66.45\%) \\
\hline CRISPR repeats & 0 & 0 & 7 \\
\hline
\end{tabular}

\subsection{In Silico Identification of Bacterial Secretion Systems and Genetic Factors Involved in} Plant-Bacteria Interactions

According to the 'T346Hunter' web-based tool, only flagellar T3SS was identified although differences were found among the three olive rhizobacteria. Strains PIC73 and PIC167 showed identical TSS profiles, and the flagellar T3SS1 and T3SS2 (PIC73 containing 33 related genes and PIC167 34 genes, including $f l a, f l b, f l e, f l i, f l g$ and $f l h$ genes) were detected in their genomes. However, only the flagellar T3SS1 was found in the genome of strain PIC28 (30 related genes including mot, fle, fli, flg, $f l h$ and $f l g$ ). In addition to the detected T3SSs, genes putative coding for the T7SS or genes related to this TSS (not detectable by the 'T346hunter' tool) were found after genome annotation (WXG100 family type VII secretion target and different type VII secretion protein such as EsaA, EssB and EssC) (Supplementary Table S5). 
The 'PIFAR' open-access web-based tool allowed the identification of several genetic factors involved in plant-bacteria interactions. A summary of the number of genes and percentage of genetic factors identified in the three newly identified Bacillales strains is displayed in Figure 1. Moreover, detailed information about the different genetic factors involved in plant-bacteria interactions is shown in Table 5. The number of annotated genes involved in plant-bacteria interaction present in the Paenibacillus strains (PIC73 and PIC167) was very similar, 86 and 82, respectively (Figure 2). The same gene clusters were identified in the genomes of the two strains except for genes related to metabolism of certain compounds enabling a BCA to proliferate inside the plants, EPSs and adhesion factors, confirming the close relatedness of these two olive rhizobacteria. In contrast, the profile of genetic factors related to plant-bacteria interaction differed significantly in strain PIC28 from that in strains PIC73 and PIC167, the former harboring a lower number of this type of factors (52) than the latter. For instance, a considerably small number of PCWDEs and antibiotic-related genes were found in strain PIC28. In contrast, more siderophore- (six genes) and biofilm-related (five genes) factors were identified in the PIC28 compared to the Paenibacillus strains (one siderophore and three biofilm genes) (Figure 2). The in silico analysis also confirmed that only the genome of Bacillus sp. PIC28 harbored genes encoding for the phytohormone IAA, pigments (Rubrifacine) and type III effectors (RipAP). Besides, the genome of strain PIC73 was the only one in which a gene related to adhesion factors was identified.

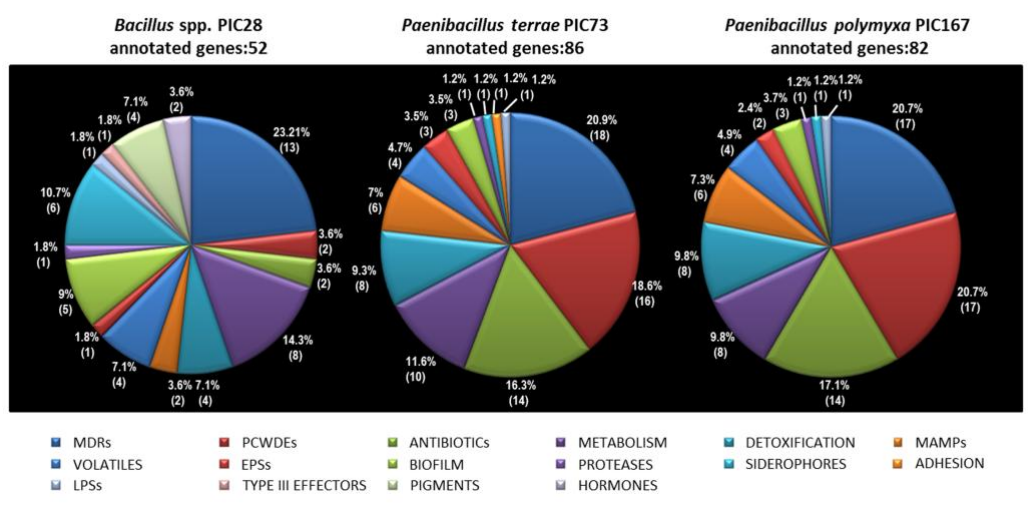

Figure 2. Number of genes and percentage of genetic factors involved in plant-bacteria interaction detected in the genomes of the olive rhizobacteria PIC28, PIC73 and PIC167.

Table 5. Genetic factors involved in plant-bacteria interaction identified in the genomes of the Bacillales strains PIC28, PIC73 and PIC167, according to the web-based tool 'PIFAR' [47].

\begin{tabular}{ccccc}
\hline & & \multicolumn{3}{c}{ Bacillales Strains } \\
\hline Genetic Factors Involved in Plant-Bacteria Interaction & PIC28 & PIC73 & PIC167 \\
\hline Proteases & htrA & + & + & + \\
\hline Cellulase & Glyco-hidro 28 & - & + & + \\
PCWDEs & manA & - & + & + \\
& Pec lyase C & + & + & + \\
& Pec lyase L & - & + & + \\
& Pectate lyase & - & + & + \\
Pectin methylesterase & - & + & + \\
Adhesion & xysB & - & + & + \\
& XadM & - & + & + \\
Detoxification & SapABCDF & - & + & + \\
\hline KatB & - & + & - \\
\hline KatE & $d p s$ & - & + & + \\
& Copper resistance cueAR & + & - & - \\
& gall & + & + & + \\
& Gpsx & + & + & + \\
& levan & + & + & + \\
\hline
\end{tabular}


Table 5. Cont.

\begin{tabular}{|c|c|c|c|c|}
\hline & & \multicolumn{3}{|c|}{ Bacillales Strains } \\
\hline \multicolumn{2}{|c|}{ Genetic Factors Involved in Plant-Bacteria Interaction } & PIC28 & PIC73 & PIC167 \\
\hline \multirow{9}{*}{ Metabolism } & $\operatorname{TrpGC}$ & + & + & + \\
\hline & Glutamate synthase gltBD & - & + & + \\
\hline & AroC & + & + & + \\
\hline & AroK & + & + & + \\
\hline & AroQ & + & - & - \\
\hline & $A s n B$ & + & + & + \\
\hline & Mqo & + & + & + \\
\hline & Purine biosynthesis purD & + & + & - \\
\hline & Purine biosynthesis purC & - & + & - \\
\hline LPSs & wzt & + & + & + \\
\hline \multirow{4}{*}{ MDRs } & ACR tran & + & + & + \\
\hline & Multi Drug Res & + & + & + \\
\hline & MatE & + & + & + \\
\hline & $O E P$ & - & + & + \\
\hline \multirow{3}{*}{ Volatiles } & Acetoin & + & + & + \\
\hline & $B u d B$ & + & + & + \\
\hline & 2,3-butanediol & + & + & + \\
\hline \multirow{6}{*}{ Antibiotics } & Fusaricidin & + & + & + \\
\hline & Amphisin & - & + & + \\
\hline & Bacilysocin & + & - & - \\
\hline & Bacillomycin D & - & + & + \\
\hline & Iturin A & - & + & + \\
\hline & Mycosubtilin & - & + & + \\
\hline \multirow{7}{*}{ MAMPs } & Chemotaxis protein cheA & + & + & + \\
\hline & Chemotaxis protein cheW & - & + & + \\
\hline & Chemotaxis protein cheY & + & + & + \\
\hline & Chemotaxis response & & & \\
\hline & regulatorprotein-glutamate cheB & - & + & + \\
\hline & CheY-P phosphatase cheC & - & + & + \\
\hline & Chemoreceptor glutamine deamidase cheD & - & + & + \\
\hline Type III effectors & RipAP & + & - & - \\
\hline \multirow{2}{*}{ Siderophores } & Bacillibactin & + & - & - \\
\hline & Arthrobactin & + & + & + \\
\hline Phytohormones & IAA2 & + & - & - \\
\hline \multirow{5}{*}{ Biofilm } & Phosphoglucomutaseprotein $\mathrm{yhxB}$ & + & + & + \\
\hline & AHL lactonase & + & + & + \\
\hline & Predicted phosphatase yqek & + & + & + \\
\hline & Signal peptidase I W sipW & + & - & - \\
\hline & ymcA & + & - & - \\
\hline Pigments & Rubrifacine & + & - & - \\
\hline
\end{tabular}

,+ presence of the genetic factor; - , absence of the genetic factor.

Finally, after manually examining the annotation of the three genomes here under study, at least 36 (PIC28), 22 (PIC73) and 24 (PIC167) genes potentially related to pathogenesis/virulence factors were detected (Supplementary Table S5). Among them, genes related to TSS7 (see above) were identified in the three strains, and three genes putatively coding for an enterotoxin were detected in the genome of strain PIC28.

\subsection{In Vitro Antagonism among Effective BCAs of VWO}

In order to assess whether the Bacillales strains here characterized could be combined (i.e., formulated as consortia) with other BCAs also effective against VWO (e.g., Pseudomonas spp. strains previously characterized by our group), in vitro dual tests with all possible strain combinations were performed (Table 6). Results varied depending on the culturing media used (PDA or LBA). In vitro antagonism assays for strains PIC25 and PIC105 were carried out only in LBA medium since these strains did not grow well in PDA medium. Only few antagonism events were observed and are summarized in Table 6. According to these results, we conclude that all Pseudomonas strains could be combined in a consortium since no antagonism was observed among them. Moreover, the two most effective BCAs from the Pseudomonas spp. group (i.e., PICF7 and PICF141), as well as P. indica PIC105, could also be combined with P. polymyxa PIC73. 
Table 6. In vitro dual tests among olive rhizobacteria showing biocontrol activity against Verticillium wilt of olive.

\begin{tabular}{|c|c|c|c|c|c|c|c|c|c|c|c|c|c|c|c|}
\hline & \multirow[b]{3}{*}{ Media } & \multicolumn{14}{|c|}{ Challenger Isolate } \\
\hline & & \multicolumn{2}{|c|}{ PIC25 } & \multicolumn{2}{|c|}{ PIC105 } & \multicolumn{2}{|c|}{ PICF7 } & \multicolumn{2}{|c|}{ PICF141 } & \multicolumn{2}{|c|}{ PIC28 } & \multicolumn{2}{|c|}{ PIC73 } & \multicolumn{2}{|c|}{ PIC167 } \\
\hline & & PDA & LBA & PDA & LBA & PDA & LBA & PDA & LBA & PDA & LBA & PDA & LBA & PDA & LBA \\
\hline & PIC25 & & & ND & - & ND & - & ND & - & ND & - & ND & + & ND & + \\
\hline & PIC105 & ND & - & & & ND & - & ND & - & ND & - & ND & - & ND & + \\
\hline & PICF7 & ND & - & ND & - & & & - & - & - & - & - & - & - & - \\
\hline \multirow[t]{4}{*}{ Target Isolate } & PICF141 & ND & - & ND & - & - & - & & & - & - & - & - & + & + \\
\hline & PIC28 & ND & - & ND & - & + & - & + & - & & & + & - & + & - \\
\hline & PIC73 & ND & - & ND & - & - & - & - & - & - & - & & & - & - \\
\hline & PIC167 & ND & - & ND & - & + & - & + & - & - & - & + & + & & \\
\hline
\end{tabular}

PDA, Potato Dextrose Agar; LBA, Luria Bertani Agar. ND, Not determined since strains PIC25 and PIC105 did not grow well in PDA medium; + , positive antagonism; - no antagonism. For experimental details see Material and Methods. 


\section{Discussion}

The development and use of BCAs against $V$. dahliae is an attractive measure within an integrated management strategy of VWO. The early introduction of the BCA, for instance at the nursery propagation stage, could 'condition' the plant to better confront subsequent infections by the pathogen's propagules existing in the planting site. Moreover, selection of BCAs sharing the same ecological niche as $V$. dahliae is a plausible approach since these microbial antagonists can compete with the pathogen for infection sites, space and nutrients [5]. For instance, in the tripartite interaction V. dahliae-oliveP. fluorescens PICF7, niche overlap between the BCA and the pathogen in planta was necessary for effective biocontrol [52]. Among the bacteria thriving in the soil/rhizosphere, some spore-forming plant growth-promoting rhizobacteria (PGPR) and/or BCAs have gained attention due to their advantages over non-spore-formers in bioproduct formulation and stable maintenance in soil. Moreover, they are usually persistent to adverse conditions and can be preserved and distributed easily [53].

The holistic strategy previously designed to identify Pseudomonas spp. strains from the olive root/rhizosphere as BCAs against VWO [16], has also been successfully implemented to in-depth characterize Gram-positive bacteria effective against the $\mathrm{D}$, highly virulent pathotype of $V$. dahliae. Eventually, three Bacillales members were selected (PIC28, PIC73 and PIC167) according to their ability to in vitro antagonize $V$. dahliae isolates and other olive pathogens. The MLSA performed enabled to identify strain PIC73 as P. polymyxa and strain PIC167 as P. terrae. However, strain PIC28 could only be assigned to the genus Bacillus and further analysis will be needed to determine the species level. Overall, results obtained from the phenotypic and metabolic analyses (e.g., Biolog Gen III) performed in our study confirmed the similarities between the two Paenibacillus strains.

The use of spores of Bacillus spp. as natural 'biopesticides' has previously been described as a safe and environmentally friendly alternative to traditional control methods. Bacillus cereus and B. subtilis (Ehrenberg) Cohn. [54] strains showed fungicidal and PGP ability when they were inoculated directly into soils as seed pretreatments. Moreover, the high survival rate of their spores in soils play an important role in its effectiveness ([55], and references therein). Likewise, one advantage of treating fields with endospore-forming bacteria such as Paenibacillus spp. is their capability to persist for long periods of time in the soil under harsh environmental conditions [56]. Representatives of the genus Bacillus has been demonstrated as BCAs of Verticillium wilts, highlighting Bacillus amyloliquefaciens Priest et al. and B. subtilis strains. For instance, B. amyloliquefaciens 5-127 reduced the percentage of diseased leaves in eggplants challenged with Verticillium dahliae in the greenhouse, and also decreased the DI in potato under field conditions [9]. Bacillus strains have been also demonstrated to be effective against Verticillium wilt in oilseed rape, cotton and strawberry [5]. Only a few studies have been focused on biological control of Verticillium wilt by Bacillales members in woody plants. Thus, some $B$. subtilis strains isolated from healthy maple trees were checked in a greenhouse against $V$. dahliae in this tree species, and disease reduction was reported [57]. The genus Paenibacillus is currently gaining interest as BCA of a range of plant diseases [58,59]. For instance, P. alvei K-165 obtained from tomato plants cultivated in solarized soil [9] showed effective biocontrol of $V$. dahliae in eggplant under greenhouse conditions $[4,9,10,60]$. This strain was also able to control $V$. dahliae in potato plants under field conditions and in olive trees under both field and greenhouse conditions $[9,17]$. In cotton, treatment with Paenibacillus xylanilyticus YUPP-1 and P. polymyxa YUPP-8 reduced DI and disease severity [61].

Results from in vitro antagonism assays showed differences depending on the culture medium used (PDA or NA). The influence of the culture media on the results of in vitro antagonism tests has been previously reported [16,62], a likely consequence of the effects on antagonistic bacteria of specific nutritional factors present in the used media. According to our in vitro antagonism tests, the most promising olive rhizobacteria to be used as BCAs against VWO would be the Paenibacillus spp. strains, particularly strain PIC73. Yet, these results are not enough to qualify them as effective BCAs since colonization of the target niche and biocontrol performance by a selected antagonist will be influenced by environmental factors (moisture, nutrients, $\mathrm{pH}$, temperature, etc.) and its ability to compete with 
preexisting microbial communities present in the site where it will be deployed. It is well known that the capacity of a beneficial bacterium to act as a BCA could vary between laboratory and field conditions, and that the best in vitro antagonist is not always the best BCA [63-66]. Therefore, in planta bioassays are important to qualify an in vitro antagonist as a true and effective BCA. Our independent VWO biocontrol experiments (performed under non-gnotobiotic conditions) showed that the three Bacillales members indigenous from olive roots were able to significantly reduce VWO development, and that their disease control ability was comparable to that observed for Pseudomonas spp. strains well characterized as VWO BCAs $[15,16]$. Furthermore, all of the tested BCAs are well adapted to the olive root/rhizosphere since they originated from this niche. However, that biocontrol performance slightly decreased when the disease pressure was high, particularly in the case of Bacillus sp. PIC28. Therefore, it is highly recommended that different experiments are conducted to obtain an accurate picture of the biocontrol performance of any BCA candidate.

Biocontrol activity of PGPR relies, among other mechanisms, on the production of different cell wall-degrading enzymes (e.g., chitinase, protease/elastase, and $\beta-1,3$ glucanase, etc.) that play an important role in degrading the cell walls of phytopathogens $[67,68]$. Some of these enzymes also degrade plant cell walls and some of their components can be utilized by BCAs, thereby enhancing their competitiveness during the root colonization process. The three Bacillales strains here studied were positive for protease, cellulase and $\beta$-glucosidase. Proteases play a significant role in cell wall lysis of phytopathogenic fungi, since proteolytic activity is a prerequisite to lyse whole fungal cells [69]. Microorganisms displaying cellulase and protease activities do not only play a role in organic matter decomposition and PGP, but also contribute to disease suppression by inhibiting fungal growth [70]. Only Paenibacillus spp. strains PIC73 and PIC167 strains showed chitinase, amylase and xylanase activities. Chitinases lyse fungal cell wall through degradation of the chitin polymer present in fungal cell walls [71]. Strain PIC73 was the only one to show phosphatase and glucanase activities, although at very low levels. Phosphatases mediate the release of inorganic $P$ from organically bound P returned to soil [72], increasing the root system and thus contributing to the growth of the plant. Glucanases participate in the degradation of cell walls in fungi, yeasts and plants [73]. Complementing this phenotypic characterization, in silico analysis revealed that the genome of Bacillus sp. PIC28 harbored a considerably lower number of genes potentially coding for cell wall-degrading enzymes (as well as antibiotics) than the two Paenibacillus strains. The ability to produce fungal cell wall-degrading enzymes and a broad spectrum of antibiotics seem to be common to aerobic spore-forming bacteria [74].

Paenibacillus terrae PIC167 was the only strain displaying phytase activity. Phytases catalyze the hydrolysis of phytic acid, releasing a utilizable form of inorganic phosphorus $(\mathrm{P})$ to the plants [75]. Rhizosphere bacteria with phytase activity have been isolated and proposed to promote plant growth in soils with high content of organic P [76]. Another trait traditionally associated with PGPR is the production of the phytohormone IAA. In silico analysis revealed the presence of two genes related to IAA biosynthesis in the genome of Bacillus sp. PIC28. However, production of IAA by this strain could not be demonstrated. Some PGPR elicit induced systemic resistance by emission of volatile organic compounds including short chain alcohols, acetoin, and 2,3-butanediol [77]. In silico analysis predicted the ability to produce several volatile compounds, including 2,3-butanediol, for the three Bacillales strains. Indeed, production of this volatile was confirmed for all of them; 2,3-butanediol produced by Bacillus spp. is suggested to be involved in plant protection [78]. Different types of siderophores promote the growth of several plant species and increase their yield by enhancing iron uptake in plants [79]. Additionally, siderophore-producing microorganisms can suppress some soil-borne fungal pathogens through a siderophore-mediated iron competition mechanism. Genes putatively involved in siderophore(s) biosynthesis were detected by in silico analysis of the genomes of the three Bacillales strains. Moreover, siderophore activity was confirmed by the CAS (Chrome Azurol S) for all of them (Table 3), Bacillus sp. PIC28 always showing much bigger orange halos than those observed for the Paenibacillus strains. 
Biofilm formation by beneficial strains of Bacillus spp. and Paenibacillus spp. is known to improve their biocontrol abilities [80-82]. Biofilms facilitate the development of a microhabitat that protects bacteria against a/biotic stresses [83,84], enhancing root competitiveness of bacteria as well. The presence of genetic factors related to biofilm development has been predicted for strains PIC28, PIC73 and PIC167, although the number of genes related to this trait was higher in strain PIC28. The presence of TSSs in the newly identified Bacillales members of the olive roots was also investigated by in silico analysis. Secretion systems in biocontrol bacteria have been related to plant root colonization, rhizosphere competence, environmental competition or defense against pathogens [85-87]. According to 'T346hunter' predictions, only the flagellar-T3SS was detected in the three genomes analyzed. It is worth mentioning that 'T346hunter' and 'PIFAR' web-based tools only detect positive matches for (nearly) complete gene clusters, and that factors defined by several genes are reported only if at least $90 \%$ of such genes are identified within a given genome $[47,48]$. Many Gram-positive bacteria also produce a specialized protein secretion machinery termed the type VII secretion system (T7SS) that is not detected by the 'T346Hunter' tool. Genes related to T7SS have been detected during the examination of the annotated genomes. T7SS are widespread in representatives of the phlya Actinobacteria and Firmicutes, and affect a range of bacterial processes including virulence, sporulation, conjugation, and cell wall stability [88]. Bioinformatics analyses have also predicted that this TSS is present in non-pathogenic bacteria [89]. WXG-100-encoding genes have also been identified in different species of the genus Bacillus, both in the non-pathogenic species B. subtilis and in pathogenic representatives of B. cereus, B. thuringiensis and Bacillus anthracis Cohn. [90,91]. Although some T7SSs can contribute to virulence, not all of these systems function in virulence or even in secretion of substrates. However, the biological functions of several type VII-secreted substrates and effector molecules are still being investigated. Finally, when the annotated genomes here reported were manually and thoroughly checked, genes putatively coding for pathogenicity/virulence factors were found, Bacillus sp. PIC28 being the strain harboring the largest number of genes potentially related with deleterious, non-desirable effects including three genes involved in enterotoxin synthesis. This fact must be carefully examined regarding the use of this strain in biocontrol frameworks.

Recent trends in biocontrol of plant diseases have focused on the development and use of consortia of beneficial microorganisms [25,92]. This approach may improve the efficacy, reliability and consistency of individual microbe-based biocontrol tools [93]. For instance, the mixture of two Bacillus strains increased protection in tomato and pepper against different pathogens [94]. Also, the application of a consortium of three rhizobacteria, B. cereus AR156, B. subtilis SM21 and Serratia sp. XY21, resulted in higher biocontrol efficacy against Verticillium wilt in cotton compared to the outcomes observed with individual treatments [95]. To be formulated in a consortium, microorganisms in the mixture must not show antagonism among them [96-98]. Olive roots are a powerful reservoir of BCAs against VWO, mainly Pseudomonas spp. [13,16] and Bacillales (this study) strains. In order to check whether these BCAs could be formulated as consortia, the absence of antagonism among them was assessed. Results showed that, for instance, a consortium consisting of Pseudomonas spp. strains was feasible since no incompatibilities were detected among them. Moreover, a consortium based on the two most effective Pseudomonas strains (PICF7 and PICF141) $[15,16]$ and P. polymyxa strain PIC73 would also be interesting to be tested in future biocontrol assays. These combinations would provide an array of BCAs colonizing different microhabitats or sites of the olive root/rhizosphere, thereby enhancing competition for the colonization sites also used by $V$. dahliae. Moreover, different biocontrol mechanisms (antagonism, competition, induction of host defense responses) $[52,53,99,100]$ could be deployed by the olive indigenous BCAs in the consortia, improving biocontrol effectiveness.

\section{Conclusions}

Three novel indigenous Bacillales strains from the olive rhizosphere and effective against the (D) pathotype of $V$. dahliae under non-gnotobitic conditions were isolated and characterized. Among them, 
strain PIC73 (P. polymyxa) was the most promising BCA according to all parameters here analyzed. Biocontrol measures based on the introduction of a single BCA, combinations of them (consortia, microbiomes), or even formulated with organic amendments, are attractive and complementary actions to be implemented within an integrated disease management strategy of VWO [1] (Figure 3). Information here generated will be useful for the future development of effective formulations against this pathogen, including consortia between the newly identified Bacillales members and Pseudomonas spp. strains previously characterized. Most of the studies on VWO biocontrol are focused on preventive (before-planting) measures, mainly working with nursery-propagated olive young plants. In our opinion, it is interesting to introduce of microbial antagonists at the production stage (nurseries) due to easier application routines and to the fact that the plant could be transferred to fields potentially infested with the pathogen with its defense mechanisms 'activated' and/or harboring a cohort of effective antagonists. Our increasing knowledge on natural inhabitants of olive roots/rhizosphere displaying biocontrol activity, that in addition could effectively be combined, will be instrumental to also develop palliative (post-planting) measures to be implemented in a more effective and consistent way under field conditions.

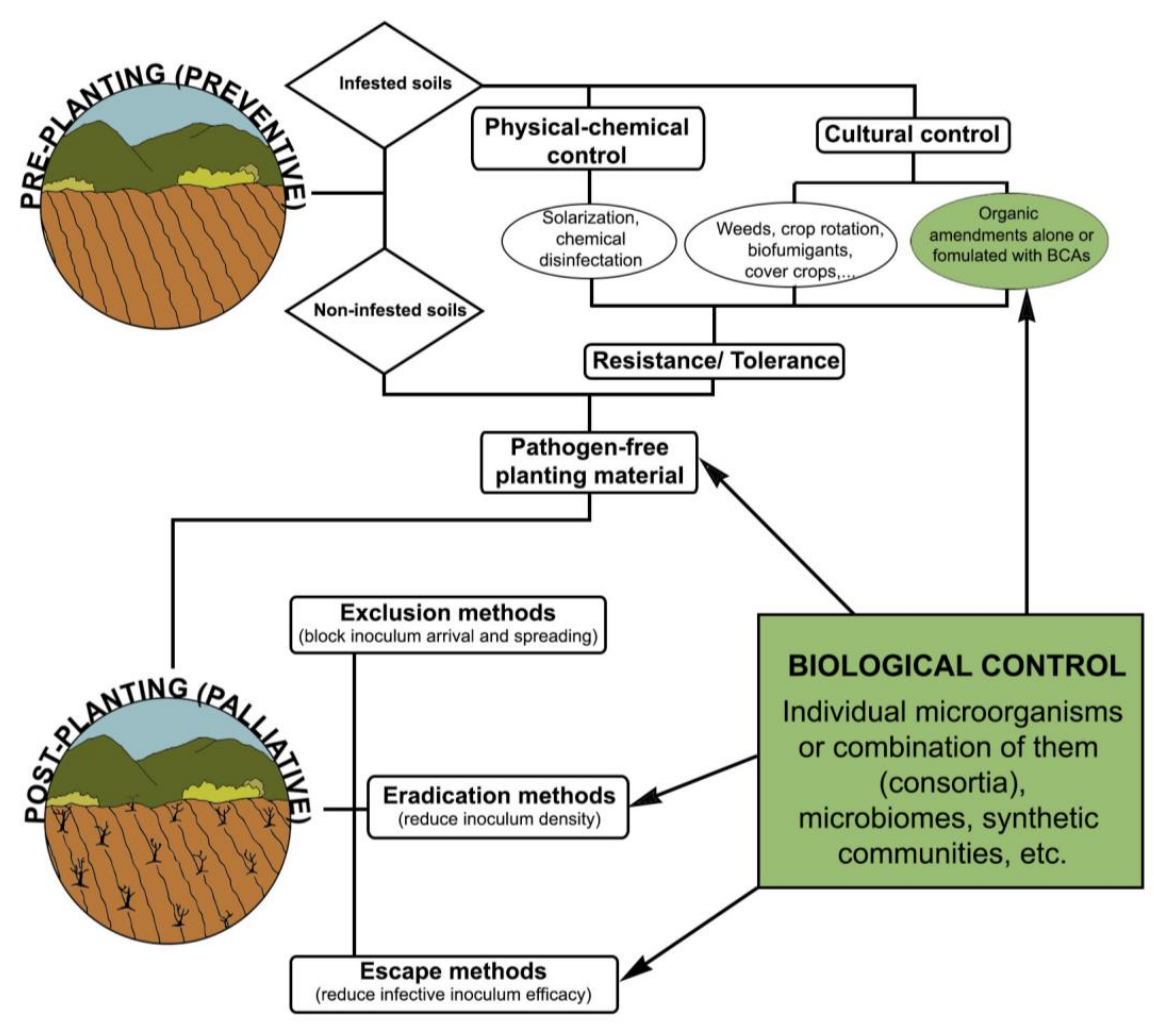

Figure 3. Biological control measures within and integrated management strategy of Verticillium wilt of olive (based on López-Escudero and Mercado-Blanco [1]).

Supplementary Materials: The following tables are available online at http:/ / www.mdpi.com/2077-0472/8/ 7/90/s1. Table S1: Biochemical analysis of strains PIC28, PIC73 and PIC167 using Biolog GEN III Microplate including utilization of carbon sources and chemical sensibilities; Table S2: General information of the three genome sequence projects; Table S3: Predicted genes annotated in the genomes of strains PIC28, PIC73 and PIC167; Table S4: Number of genes associated with GO functional categories; and Table S5: Potential pathogenesis-related genes identified in annotated genomes of strains PIC28, PIC73 and PIC167.

Author Contributions: J.M.-B. conceived the study. All authors participated in the experimental design. C.G.-L.C., D.R.-R., P.P.-T., A.V.-C., A.R., and J.M.-B. performed in planta bioassays and conducted experiments aimed to identify and characterize bacterial strains. D.R.-R and A.V.-C. carried out in vitro antagonism tests. G.L. and J.C.T. performed bioinformatics analyses. C.G.-L.C and J.M.-B. wrote the article. All authors have approved the final version. 
Funding: Supported by grants P12-AGR-667 (Junta de Andalucía) and RECUPERA 2020 (MINECO-CSIC agreement), both co-financed by ERDF from the EU.

Conflicts of Interest: The authors declare no conflict of interest. The founding sponsors had no role in the design of the study; in the collection, analyses, or interpretation of data; in the writing of the manuscript, and in the decision to publish the results.

\section{References}

1. López-Escudero, F.J.; Mercado-Blanco, J. Verticillium wilt of olive: A case study to implement an integrated strategy to control a soil-borne pathogen. Plant Soil 2011, 344, 1-50. [CrossRef]

2. Al-Achi, B.J.; Platsouka, E.; Levy, S.B. Competitive colonization between Pseudomonas species in sterile soils. Curr. Microbiol. 1991, 23, 97-104. [CrossRef]

3. Schloss, P.D.; Handelsman, J. Toward a census of bacteria in soil. PLoS Comput. Biol. 2006, 2, e92. [CrossRef] [PubMed]

4. Angelopoulou, D.J.; Naska, E.J.; Paplomatas, E.J.; Tjamos, S.E. Biological control agents (BCAs) of verticillium wilt: Influence of application rates and delivery method on plant protection, triggering of host defence mechanisms and rhizosphere populations of BCAs. Plant Pathol. 2014, 63, 1062-1069. [CrossRef]

5. Deketelaere, S.; Tyvaert, L.; Franca, S.C.; Hofte, M. Desirable traits of a good biocontrol agent against Verticillium wilt. Front. Microbiol. 2017, 8, 1186. [CrossRef] [PubMed]

6. Berg, G.; Knaape, C.; Ballin, G.; Seidel, D. Biological control of Verticillium dahliae kleb. by naturally occurring rhizosphere bacteria. Arch. Phytopathol. Plant Protect. 1994, 29, 249-262. [CrossRef]

7. Zhengjun, X.; Benkang, G.; Aiming, W. Studies on biocontrol of Verticillium wilt of cotton by endophytic and rhizosphere bacteria. In Advances in Biological Control of Plant Diseases; Wenhua, T., Cook, R.J., Rovira, A., Eds.; China Agricultural University Press: Beijing, China, 1996; pp. 125-127.

8. Berg, G.; Lottmann, J. Bacterial antagonists to Verticillium longisporum in the rhizosphere of oilseed rape. In Advances in Verticillium Research and Disease Management; Tjamjamosos, E.C., Rowe, R.C., Heale, J.B., Fravel, D.R., Eds.; The American Phytopathological Society: St. Paul, MN, USA, 2000; pp. 240-243.

9. Tjamos, E.C.; Tsitsigiannis, D.I.; Tjamos, S.E.; Antoniou, P.P.; Katinakis, P. Selection and screening of endorhizosphere bacteria from solarized soils as biocontrol agents against Verticillium dahliae of solanaceous hosts. Eur. J. Plant Pathol. 2004, 110, 35-44. [CrossRef]

10. Antonopoulos, D.F.; Tjamos, S.E.; Antoniou, P.P.; Rafeletos, P.; Tjamos, E.C. Effect of Paenibacillus alvei, strain K165, on the germination of Verticillium dahliae microsclerotia in planta. Biol. Control 2008, 46, 166-170. [CrossRef]

11. Malandraki, I.; Tjamos, S.E.; Pantelides, I.; Paplomatas, E.J. Thermal inactivation of compost suppressiveness implicates possible biological factors in disease management. Biol. Control. 2008, 44, 180-187. [CrossRef]

12. Veloso, J.; Díaz, J. Fusarium oxysporum Fo47 confers protection to pepper plants against Verticillium dahliae and Phytophthora capsici, and induces the expression of defence genes. Plant Pathol. 2012, 61, 281-288. [CrossRef]

13. Mercado-Blanco, J.; Rodríguez-Jurado, D.; Hervás, A.; Jiménez-Díaz, R.M. Suppression of Verticillium wilt in olive planting stocks by root-associated fluorescent Pseudomonas spp. BioControl 2004, 30, 474-486. [CrossRef]

14. Prieto, P.; Navarro-Raya, C.; Valverde-Corredor, A.; Amyotte, S.G.; Dobinson, K.F.; Mercado-Blanco, J. Colonization process of olive tissues by Verticillium dahliae and its in planta interaction with the biocontrol root endophyte Pseudomonas fluorescens PICF7. Microb. Biotechnol. 2009, 2, 499-511. [CrossRef] [PubMed]

15. Maldonado-González, M.M.; Schilirò, E.; Prieto, P.; Mercado-Blanco, J. Endophytic colonization and biocontrol performance of Pseudomonas fluorescens PICF7 in olive (Olea europaea L.) are determined neither by pyoverdine production nor swimming motility. Environ. Microbiol. 2015, 17, 3139-3153. [CrossRef] [PubMed]

16. Gómez-Lama Cabanás, C.; Legarda, G.; Ruano-Rosa, D.; Pizarro-Tobías, P.; Valverde-Corredor, A.; Niqui, J.L.; Triviño, J.C.; Roca, A.; Mercado-Blanco, J. Indigenous Pseudomonas spp. strains from the olive (Olea europaea L.) rhizosphere as effective biocontrol agents against Verticillium dahliae: From the host roots to the bacterial genomes. Front. Microbiol. 2018, 9, 277. [CrossRef] [PubMed]

17. Markakis, E.A.; Tjamos, S.E.; Antoniou, P.P.; Paplomatas, E.J.; Tjamos, E.C. Biological control of Verticillium wilt of olive by Paenibacillus alvei, strain K165. BioControl 2016, 61, 293-303. [CrossRef]

18. Varo, A.; Raya-Ortega, M.C.; Trapero, A. Selection and evaluation of micro-organisms for biocontrol of Verticillium dahliae in olive. J. Appl. Microbiol. 2016, 121, 767-777. [CrossRef] [PubMed] 
19. European Commission. Available online: https://ec.europa.eu/food/plant/pesticides/ (accessed on 19 March 2018).

20. Cook, R.J. Biological control of plant pathogens: Theory and application. Phytopathology 1985, 75, 25-29. [CrossRef]

21. Berendsen, R.L.; Pieterse, C.M.J.; Bakker, P.A.H.M. The rhizosphere microbiome and plant health. Trends Plant Sci. 2012, 17, 478-486. [CrossRef] [PubMed]

22. Spence, C.; Alff, E.; Johnson, C.; Ramos, C.; Donofrio, N.; Sundaresan, V.; Bais, H. Natural rice rhizospheric microbes suppress rice blast infections. BMC Plant Biol. 2014, 14, 130. [CrossRef] [PubMed]

23. Mazzola, M.; Freilich, S. Prospects for biological soilborne disease control: Application of indigenous versus synthetic microbiomes. Phytopathology 2017, 107, 256-263. [CrossRef] [PubMed]

24. Mercado-Blanco, J.; Abrantes, I.; Barra Caracciolo, A.; Bevivino, A.; Ciancio, A.; Grenni, P.; Hrynkiewicz, K.; Kredics, L.; Proença, D.N. Belowground microbiota and the health of tree crops. Front. Microbiol. 2018, 9, 1006. [CrossRef] [PubMed]

25. Sarma, B.K.; Yadav, S.K.; Singh, S.; Singh, H.B. Microbial consortium-mediated plant defense against phytopathogens: Readdressing for enhancing efficacy. Soil Biol. Biochem. 2015, 87, 25-33. [CrossRef]

26. Leyva-Pérez, M.D.L.O.; Jiménez-Ruiz, J.; Gómez-Lama Cabanás, C.; Valverde-Corredor, A.; Barroso, J.B.; Luque, F.; Mercado-Blanco, J. Tolerance of olive (Olea europaea) cv Frantoio to Verticillium dahliae relies on both basal and pathogen-induced differential transcriptomic responses. New Phytol. 2018, 217, 671-686. [CrossRef] [PubMed]

27. Ruano-Rosa, D.; Valverde-Corredor, A.; Gómez-Lama Cabanás, C.; Sesmero, R.; Mercado-Blanco, J. What lies beneath: Root-associated bacteria to improve the growth and health of olive trees. In Soil Biological Communities and Ecosystem Resilience; Sustainability in Plant and Crop Protection Series; Lukac, M., Grenni, P., Gamboni, M., Eds.; Springer: Cham, Switzerland, 2017; pp. 107-122.

28. National Center for Biotechnology Information. Available online: http://www.ncbi.nlm.nih.gov/ (accessed on 20 January 2018).

29. Kumar, S.; Stecher, G.; Tamura, K. MEGA7: Molecular evolutionary genetics analysis version 7.0 for bigger data sets. Mol. Biol. Evol. 2016, 33, 1870-1874. [CrossRef] [PubMed]

30. Tamura, K.; Nei, M.; Kumar, S. Prospects for inferring very large phylogenies by using the Neighbor-Joining method. Proc. Natl. Acad. Sci. USA 2004, 101, 11030-11035. [CrossRef] [PubMed]

31. Martínez-García, P.M.; Ruano-Rosa, D.; Schilirò, E.; Prieto, P.; Ramos, C.; Rodríguez-Palenzuela, P.; Mercado-Blanco, J. Complete genome sequence of Pseudomonas fluorescens strain PICF7, an indigenous root endophyte from olive (Olea europaea L.) and effective biocontrol agent against Verticillium dahliae. Stand. Genom. Sci. 2015, 10, 10. [CrossRef] [PubMed]

32. Campbell, C.L.; Madden, L.V. Introduction to Plant Disease Epidemiology; John Wiley \& Sons: New York, NY, USA, 1990. [CrossRef]

33. Babraham Bioinformatics. Available online: http://www.bioinformatics.bbsrc.ac.uk/projects/fastqc (accessed on 3 January 2018).

34. Aronesty, E. Ea-Utils: Command-Line Tools for Processing Biological Sequencing Data. 2011. Available online: https:/ / github.com/ExpressionAnalysis/ea-utils (accessed on 7 January 2018).

35. Martin, M. Cutadapt removes adapter sequences from high-throughput sequencing reads. EMBnet. J. 2011, 17, 10-12. [CrossRef]

36. Magoč, T.; Salzberg, S. FLASH: Fast length adjustment of short reads to improve genome assemblies. Bioinformatics 2011, 27, 2957-2963. [CrossRef] [PubMed]

37. Li, D.; Luo, R.; Liu, C.M.; Leung, C.M.; Ting, H.F.; Sadakane, K.; Yamashita, H.; Lam, T.W. MEGAHIT v1.0: A fast and scalable metagenome assembler driven by advanced methodologies and community practices. Methods 2016, 102, 3-11. [CrossRef] [PubMed]

38. Zerbino, D.R.; Birney, E. Velvet: Algorithms for de novo short read assembly using de Bruijn graphs. Genome Res. 2008, 18, 821-829. [CrossRef] [PubMed]

39. Kurtz, S.; Phillippy, A.; Delcher, A.L.; Smoot, M.; Shumway, M.; Antonescu, C.; Salzberg, S.L. Versatile and open software for comparing large genomes. Genome Biol. 2004, 5, R12. [CrossRef] [PubMed]

40. Delcher, A.L.; Harmon, D.; Kasif, S.; White, O.; Salzberg, S.L. Improved microbial gene identification with GLIMMER. Nucleic Acids Res. 1999, 27, 4636-4641. [CrossRef] [PubMed] 
41. Altschul, S.F.; Madden, T.L.; Schäffer, A.A.; Zhang, J.; Zhang, Z.; Miller, W.; Lipman, D.J. Gapped BLAST and PSI-BLAST: A new generation of protein database search programs. Nucleic Acids Res. 1997, 25, 3389-3402. [CrossRef] [PubMed]

42. UniProt. Available online: http://www.uniprot.org/ (accessed on 15 January 2018).

43. Ashburner, M.; Ball, C.A.; Blake, J.A.; Botstein, D.; Butler, H.; Cherry, J.M.; Davis, A.P.; Dolinski, K.; Dwight, S.S.; Eppig, J.T.; et al. Gene ontology: Tool for the unification of biology. Nat. Genet. 2000, 25, 25-29. [CrossRef] [PubMed]

44. Van Hijum, S.A.F.T.; Zomer, A.L.; Kuipers, O.P.; Kok, J. Projector 2: Contig mapping for efficient gap-closure of prokaryotic genome sequence assemblies. Nucleic Acids Res. 2005, 33, W560-W566. [CrossRef] [PubMed]

45. Kanehisa, M.; Furumichi, M.; Tanabe, M.; Sato, Y.; Morishima, K. KEGG: New perspectives on genomes, pathways, diseases and drugs. Nucleic Acids Res. 2017, 45, D353-D361. [CrossRef] [PubMed]

46. Finn, R.D.; Mistry, J.; Tate, J.; Coggill, P.; Heger, A.; Pollington, J.E.; Gavin, O.L.; Gunasekaran, P.; Ceric, G.; Forslund, K.; et al. The Pfam protein families database. Nucleic Acids Res. 2010, 38, D211-D222. [CrossRef] [PubMed]

47. Martínez-García, P.M.; López-Solanilla, E.; Ramos, C.; Rodríguez-Palenzuela, P. Prediction of bacterial associations with plants using a supervised machine-learning approach. Environ. Microbiol. 2016, 18, 4847-4861. [CrossRef] [PubMed]

48. Martínez-García, P.M.; Ramos, C.; Rodríguez-Palenzuela, P. T346Hunter: A novel web-based tool for the prediction of Type III, Type IV and Type VI secretion systems in bacterial genomes. PLoS ONE 2015, 10, e0119317. [CrossRef] [PubMed]

49. Helgason, E.; Okstad, O.A.; Caugant, D.A.; Johansen, H.A.; Fouet, A.; Mock, M.; Hegna, I.; Kolstø, A.B. Bacillus anthracis, Bacillus cereus, and Bacillus thuringiensis-One species on the basis of genetic evidence. Appl. Environ. Microbiol. 2000, 66, 2627-2630. [CrossRef] [PubMed]

50. Shin, S.H.; Kim, S.; Kim, J.Y.; Song, H.Y.; Cho, S.J.; Kim, D.R.; Lee, K.-I.; Lim, H.K.; Park, N.-J.; Hwang, I.T.; et al. Genome Sequence of Paenibacillus terrae HPL-003, a Xylanase-Producing Bacterium Isolated from Soil Found in Forest Residue. J. Bacteriol. 2012, 194, 1266. [CrossRef] [PubMed]

51. Eastman, A.W.; Heinrichs, D.E.; Yuan, Z.C. Comparative and genetic analysis of the four sequenced Paenibacillus polymyxa genomes reveals a diverse metabolism and conservation of genes relevant to plant-growth promotion and competitiveness. BMC Genom. 2014, 15, 851. [CrossRef] [PubMed]

52. Gómez-Lama Cabanás, C.; Sesmero, R.; Valverde-Corredor, A.; López-Escudero, F.J.; Mercado-Blanco, J. A split-root system to assess biocontrol effectiveness and defense-related genetic responses in above-ground tissues during the tripartite interaction Verticillium dahliae olive-Pseudomonas fluorescens PICF7 in roots. Plant Soil 2017, 417, 433-452. [CrossRef]

53. Pliego, C.; Kamilova, F.; Lugtenberg, B. Plant growth-promoting bacteria: Fundamentals and exploitation. In Bacteria in Agrobiology: Crop Ecosystems; Maheshwari, D.K., Ed.; Springer: Berlin/Heidelberg, Germany, 2011; pp. 295-343.

54. Emmert, E.A.B.; Handelsman, J. Biocontrol of plant disease: A (Gram-) positive perspective. FEMS Microbiol. Lett. 1999, 171, 1-9. [CrossRef] [PubMed]

55. Nicholson, W.L. Roles of Bacillus endospores in the environment. Cell Mol. Life Sci. 2002, 59, $410-416$. [CrossRef] [PubMed]

56. Duca, D.; Lorv, J.; Patten, C.L.; Rose, D.; Glick, B.R. Indole-3-acetic acid in plant-microbe interactions. Antonie Leeuwenhoek 2014, 106, 85-125. [CrossRef] [PubMed]

57. Hall, T.J.; Schreiber, L.R.; Leben, C. Effects of xylemcolonizing Bacillus spp. on Verticillium wilt in Maples. Plant Dis. 1986, 70, 521. [CrossRef]

58. Lal, S.; Tabacchioni, S. Ecology and biotechnological potential of Paenibacillus polymyxa: A minireview. Indian J. Microbiol. 2009, 49, 2-10. [CrossRef] [PubMed]

59. Rybakova, D.; Schmuck, M.; Wetzlinger, U.; Varo-Suarez, A.; Murgu, O.; Müller, H.; Berg, G. Kill or cure? The interaction between endophytic Paenibacillus and Serratia strains and the host plant is shaped by plant growth conditions. Plant Soil 2016, 405, 65-79. [CrossRef]

60. Markakis, E.A.; Tjamos, S.E.; Chatzipavlidis, I.; Antoniou, P.P.; Paplomatas, E.J. Evaluation of compost amendments for control of Vascular Wilt diseases. J. Phytopathol. 2008, 156, 622-627. [CrossRef]

61. Yang, P.; Sun, Z.X.; Liu, S.Y.; Lu, H.X.; Zhou, Y.; Sun, M. Combining antagonistic endophytic bacteria in different growth stages of cotton for control of Verticillium wilt. Crop Prot. 2013, 47, 17-23. [CrossRef] 
62. Trivedi, P.; Pandey, A.; Palni, L.M.S. In vitro evaluation of antagonistic properties of Pseudomonas corrugata. Microbiol. Res. 2008, 163, 329-336. [CrossRef] [PubMed]

63. Mercado-Blanco, J.; Bakker, P. Interactions between plants and beneficial Pseudomonas spp.: Exploiting bacterial traits for crop protection. Antonie Leeuwenhoek 2007, 92, 367-389. [CrossRef] [PubMed]

64. Errakhi, R.; Bouteau, F.; Lebrihi, A.; Barakate, M. Evidences of biological control capacities of Streptomyces spp. against Sclerotium rolfsii responsible for damping-off disease in sugar beet (Beta vulgaris L.). World J. Microbiol. Biotechnol. 2007, 23, 1503-1509. [CrossRef]

65. Goudjal, Y.; Toumatia, O.; Yekkour, A.; Sabaou, N.; Mathieu, F.; Zitouni, A. Biocontrol of Rhizoctonia solani damping-off and promotion of tomato plant growth by endophytic actinomycetes isolated from native plants of Algerian Sahara. Microbiol. Res. 2014, 169, 59-65. [CrossRef] [PubMed]

66. Martín, J.A.; Macaya-Sanz, D.; Witzell, J.; Blumenstein, K.; Gil, L. Strong in vitro antagonism by elm xylem endophytes is not accompanied by temporally stable in planta protection against a vascular pathogen under field conditions. Eur. J. Plant Pathol. 2015, 142, 185-196. [CrossRef]

67. Aktuganov, G.; Jokela, J.; Kivelä, H.; Khalikova, E.; Melentjev, A.; Galimzianova, N.; Kuzmina, L.; Kouvonen, P.; Himanen, J.P.; Susi, P.; et al. Isolation and identification of cyclic lipopeptides from Paenibacillus ehimensis, strain IB-X-b. J. Chromatogr. B 2014, 8, 9-16. [CrossRef] [PubMed]

68. Muleta, D.; Assefa, F.; Granhall, U. In vitro antagonism of rhizobacteria isolated from Coffea arabica L. against emerging fungal coffee pathogens. Eng. Life Sci. 2007, 7, 577-586. [CrossRef]

69. Elad, Y.; Kapat, A. The role of Trichoderma harzianum protease in the biocontrol of Botrytis cinerea. Eur. J. Plant Pathol. 1999, 105, 177-189. [CrossRef]

70. Kavamura, V.N.; Santos, S.N.; da Silva, J.L.; Parma, M.M.; Ávila, L.A.; Visconti, A.; Zucchi, T.D.; Taketani, R.G.; Andreote, F.D.; de Melo, I.S. Screening of Brazilian cacti rhizobacteria for plant growth promotion under drought. Microbiol. Res. 2013, 168, 183-191. [CrossRef] [PubMed]

71. Shaikh, S.S.; Sayyed, R.Z. Role of plant growth-promoting rhizobacteria and their formulation in biocontrol of plant diseases. In Plant Microbes Symbiosis: Applied Facets; Arora, N.K., Ed.; Springer: New Delhi, India, 2015; pp. 337-351.

72. Dhruva Kumar, J.H.A.; Sharha, G.D.; Mishra, R.R. Soil microbial population numbers and enzyme activities in relation to altitude and forest degradation. Soil Biol. Biochem. 1992, 24, 761-767. [CrossRef]

73. Pang, Z.; Otaka, K.; Suzuki, Y.; Gotoand, K.; Ohnishi, M. Purification and characterization of an endo-1,3,- $\beta$-glucanase from Arthrobacter sp. J. Biol. Macromol. 2004, 4, 57-66.

74. Bach, E.; Seger, G.D.S.; Fernandes, G.C.; Lisboa, B.B.; Passaglia, L.M.P. Evaluation of biological control and rhizosphere competence of plant growth promoting bacteria. Appl. Soil Ecol. 2016, 99, 141-149. [CrossRef]

75. Singh, B.; Satyanarayana, T. Microbial phytases in phosphorus acquisition and plant growth promotion. Physiol. Mol. Biol. Plants 2011, 17, 93-103. [CrossRef] [PubMed]

76. Singh, P.; Kumar, V.; Agrawal, S. Evaluation of phytase producing bacteria for their plant growth promoting activities. Int. J. Microbiol. 2014, 2014, 426483. [CrossRef] [PubMed]

77. Lee, B.; Lee, S.; Ryu, C.M. Foliar aphid feeding recruits rhizosphere bacteria and primes plant immunity against pathogenic and non-pathogenic bacteria in pepper. Ann. Bot. 2012, 110, 281-290. [CrossRef] [PubMed]

78. Ryu, C.M.; Faragt, M.A.; Hu, C.H.; Reddy, M.S.; Wei, H.X.; Pareì, P.W.; Kloepper, J.W. Bacterial volatiles promote growth in Arabidopsis. Proc. Natl. Acad. Sci. USA 2003, 100, 4927-4932. [CrossRef] [PubMed]

79. Saha, M.; Sarkar, S.; Sarkar, B.; Sharma, B.K.; Bhattacharjee, S.; Tribediet, P. Microbial siderophores and their potential applications: A review. Environ. Sci. Pollut. Res. 2016, 23, 3984. [CrossRef] [PubMed]

80. Bais, H.P.; Fall, R.; Vivanco, J.M. Biocontrol of Bacillus subtilis against infection of Arabidopsis roots by Pseudomonas syringae is facilitated by biofilm formation and surfactin production. Plant Physiol. 2004, 134, 307-319. [CrossRef] [PubMed]

81. Chen, Y.; Yan, F.; Chai, Y.; Liu, H.; Kolter, R.; Losick, R.; Guo, J.-H. A Bacillus subtilis sensor kinase involved in triggering biofilm formation on the roots of tomato plants. Mol. Microbiol. 2012, 85, 418-430. [CrossRef] [PubMed]

82. Haggag, W.M.; Timmusk, S. Colonization of peanut roots by biofilm-forming Paenibacillus polymyxa initiates biocontrol against crown rot disease. J. Appl. Microbiol. 2008, 104, 961-969. [CrossRef] [PubMed] 
83. Mavrodi, D.V.; Parejko, J.A.; Mavrodi, O.V.; Kwak, Y.S.; Weller, D.M.; Blankenfeldt, W.; Thomashow, L.S. Recent insights into the diversity, frequency and ecological roles of phenazines in fluorescent Pseudomonas spp. Environ. Microbiol. 2013, 15, 675-686. [CrossRef] [PubMed]

84. Raaijmakers, J.; Mazzola, M. Diversity and natural functions of antibiotics produced by beneficial and pathogenic soil bacteria. Annu. Rev. Phytopathol. 2012, 50, 403-424. [CrossRef] [PubMed]

85. Rezzonico, F.; Binder, C.; Défago, G.; Moënne-Loccoz, Y. The type III secretion system of biocontrol Pseudomonas fluorescens KD targets the phytopathogenic Chromista Pythium ultimum and promotes cucumber protection. Mol. Plant Microbe Interact. 2005, 18, 991-1001. [CrossRef] [PubMed]

86. Matz, C.; Moreno, A.M.; Alhede, M.; Manefield, M.; Hauser, A.R.; Givskov, M.; Kjelleberg, S. Pseudomonas aeruginosa uses type III secretion system to kill biofilm-associated amoebae. ISME J. 2008, 2, 843-852. [CrossRef] [PubMed]

87. Mavrodi, D.V.; Joe, A.; Mavrodi, O.V.; Hassan, K.A.; Weller, D.M.; Paulsen, I.T.; Loper, J.E.; Alfano, J.R.; Thomashow, L.S. Structural and functional analysis of the type III secretion system from Pseudomonas fluorescens Q8r1-96. J. Bacteriol. 2011, 193, 177-189. [CrossRef] [PubMed]

88. Akpe San Roman, S.; Facey, P.D.; Fernandez-Martinez, L.; Rodriguez, C.; Vallin, C.; Del Sol, R.; Dyson, P. A heterodimer of $E s x A$ and $E s x B$ is involved in sporulation and is secreted by a type VII secretion system in Streptomyces coelicolor. Microbiology 2010, 156, 1719-1729. [CrossRef] [PubMed]

89. Pallen, M.J. The ESAT-6/WXG100 superfamily and a new Gram-positive secretion system? Trends Microbiol. 2002, 10, 209-212. [CrossRef]

90. Baptista, C.; Barreto, H.C.; Sao-Jose, C. High levels of DegU-P activate an Esat-6-like secretion system in Bacillus subtilis. PLoS ONE 2013, 8, e67840. [CrossRef] [PubMed]

91. Huppert, L.A.; Ramsdell, T.L.; Chase, M.R.; Sarracino, D.A.; Fortune, S.M.; Burton, B.M. The ESX system in Bacillus subtilis mediates protein secretion. PLoS ONE 2014, 9, e96267. [CrossRef] [PubMed]

92. Sarma, B.K.; Yadav, S.K.; Singh, S.; Singh, H.B. Microbial consortium-mediated plant defense against phytopathogens: Readdressing for enhancing efficacy. Soil Biol. Biochem. 2015, 87, 25-33. [CrossRef]

93. Berendsen, R.L; Vismans, G.; Yu, K.; Song, Y.; de Jonge, R.; Burgman, W.P.; Burmølle, M.; Herschend, J.; Bakker, P.A.H.M.; Pieterse, C.M.J. Disease-induced assemblage of a plant-beneficial bacterial consortium. ISME J. 2018. [CrossRef] [PubMed]

94. Stockwell, V.O.; Johnson, K.B.; Sugar, D.; Loper, J.E. Mechanistically compatible mixtures of bacterial antagonists improve biological control of fire blight of pear. Phytopathology 2001, 101, 113-123. [CrossRef] [PubMed]

95. Jetiyanon, K. Defensive-related enzyme response in plants treated with a mixture of Bacillus strains (IN937a and IN937b) against different pathogens. Biol. Control 2007, 42, 178-185. [CrossRef]

96. Yang, W.; Zheng, L.; Liu, H.-X.; Wang, K.-B.; Wang, Y.-P.; Luo, Y.-M.; Gou, J.-H. Evaluation of the effectiveness of a consortium of three plant-growth promoting rhizobacteria for biocontrol of cotton Verticillium wilt. Biocontrol Sci. Technol. 2014, 24, 489-502. [CrossRef]

97. Jain, A.; Singh, S.; Sarma, B.K.; Singh, H.B. Microbial consortium-mediated reprogramming of defence network in pea to enhance tolerance against Sclerotinia sclerotiorum. J. Appl. Microbiol. 2012, 112, 537-550. [CrossRef] [PubMed]

98. Singh, A.; Sarma, B.K.; Upadhyay, R.S.; Singh, H.B. Compatible rhizosphere microbes mediated alleviation of biotic stress in chickpea through enhanced antioxidant and phenylpropanoid activities. Microbiol. Res. 2013, 168, 33-40. [CrossRef] [PubMed]

99. Schilirò, E.; Ferrara, M.; Nigro, F.; Mercado-Blanco, J. Genetic responses induced in olive roots upon colonization by the biocontrol endophytic bacterium Pseudomonas fluorescens PICF7. PLoS ONE 2012, 7, e48646. [CrossRef] [PubMed]

100. Gómez-Lama Cabanás, C.; Schilirò, E.; Valverde-Corredor, A.; Mercado-Blanco, J. The biocontrol endophytic bacterium Pseudomonas fluorescens PICF7 induces systemic defense responses in aerial tissues upon colonization of olive roots. Front. Microbiol. 2014, 5, 427. [CrossRef] [PubMed]

(C) 2018 by the authors. Licensee MDPI, Basel, Switzerland. This article is an open access article distributed under the terms and conditions of the Creative Commons Attribution (CC BY) license (http://creativecommons.org/licenses/by/4.0/). 